\title{
Cabecinhas, R. \& Cunha, L. (Eds.) (2008). Comunicação intercultural. Perspectivas, dilemas e desafios. Porto: Campo das Letras.
}

\author{
Renné Oliveira França
}

Resultado da conferência "Comunicação Intercultural: Perspectivas, Dilemas e Desafios", realizada em abril de 2008 na Universidade do Minho, em Portugal, o livro Comunicação Intercultural é uma coleção de diferentes textos que contribuem para o debate sobre os desafios inerentes ao diálogo intercultural nas sociedades contemporâneas.

Comunicação Intercultural é composto por uma introdução e dez capítulos que estão organizados dentro de quatro partes que subdividem o tema principal. Por se tratar de uma obra conjunta, escrita por diferentes autores, sua narrativa é bastante variada, apresentando contributos de diferentes áreas disciplinares. Há um eixo que conduz a reflexão, apresentado na "Introdução", seguido de capítulos que analisam e estruturam, por meio de tópicos aparentemente independentes, os elementos que circundam o ponto principal. Na obra em questão isso se materializa de forma bastante evidente. O leitor encontra, já na introdução, um excelente panorama do que será abordado, constituído pela contextualização e explicitação dos objetivos e conteúdos; e os capítulos que se seguem, apesar de escritos por diferentes autores, são coerentes entre si, o que permite tanto uma leitura aleatória, como uma leitura seqüencial seguindo sua organização.

Ao se propor a discutir a comunicação intercultural, portanto algo ainda inconcluso, complexo e controverso, os diversos autores conseguem apontar - apesar das diferentes referências teóricas - alguns pontos em comum dessa problemática da sociedade contemporânea, realizando um bom diagnóstico das arestas e desequilíbrios que marcam nossa realidade (e mais especificamente, a realidade européia). São indicadas causas e conseqüências - algumas mais exploradas por uns autores do que por outros - de aspectos problemáticos das sociabilidades locais e globais, ao mesmo tempo em que, indiretamente, convida-se o leitor a percebê-los sob a ótica do Outro.

Para uma boa leitura da obra, deve-se estar sempre atento ao contexto geográfico e histórico. Dessa forma, o tema do diálogo entre culturas é melhor aproveitado em todos os seus aspectos, sejam eles políticos, econômicos, simbólicos, psicológicos ou espaciais; tal qual buscam elencar os editores. Já na "Introdução" fica clara a tentativa de contribuição para um debate mais estimulante sobre o assunto e que fuja um pouco das comuns discussões acerca da desigualdade que a reduzem de forma simplificadora.

A desigualdade decisiva que marca a relação entre diferentes grupos deve ser percebida de um modo multifocal. Na sua persistência e reprodução interferem múltiplos e diversos factores, que vão desde a ordem económica 
internacional até a diferente experiência histórica, factores permanentemente cruzados com o campo das representações sociais, isto é, com o modo como pensamos e imaginamos o mundo e as relações sociais. (p. 8)

$\mathrm{Na}$ "Introdução" estão apontados, ainda, os motivos que levaram à produção do livro, como a já citada conferência e também a celebração do Ano Europeu do Diálogo Intercultural. Nesse sentido, os editores apontam para o cuidado que se deve ter com o termo celebração, uma vez que não basta celebrar o diálogo cultural sem de fato promover um verdadeiro encontro. É na busca por alternativas a concepções pré-estabelecidas e simplificadas acerca da interculturalidade que se encontra a intenção das discussões presentes no livro. A proposta parece ser a de tentar perceber os diferentes modos de comunicar dentro de um mundo plural, e a própria estratégia de utilizar diferentes autores de diferentes nacionalidades para tal feito já revela o diálogo intercultural dentro da própria obra.

Na primeira parte, intitulada "Espaços e migrações: Fluxos leis e olhares", encontram-se três capítulos que discutem a migração. No primeiro, "Imigração e interculturalidade na União Europeia", a autora Isabel Estrada Carvalhais parte de três conceitos chaves (imigração ilegal, migração circular e boa vizinhança) para investigar a imigração na União Européia por um prisma político. O texto perpassa as contradições políticas de Estados que por um lado necessitam das imigrações para manter sua estabilidade demográfica e por outro entendem ser mais fácil investir no combate à "imigração ilegal" do que no "acolhimento" de imigrantes. A política de imigração na União Européia aparece, então, com a dificuldade de lidar com o ambivalente discurso de liberdade e acolhimento de um lado contra o medo de terrorismo e a ilegalidade de outro.

O segundo texto, de Anna Zlobina e Dario Páez, analisa as estratégias de aculturação dos imigrantes na Espanha. Com o título "Aculturación y comunicación intercultural: El caso de inmigración em España", o capítulo discute as dificuldades inerentes à integração dos imigrantes na sociedade de acolhimento sem perda a sua identidade cultural de origem. Há um duplo viés que perpassa tanto pelas sociedades que recebem quanto pelos imigrantes, que precisam se ajustar tanto no âmbito privado - onde a esfera íntima recebe o impacto de uma nova cultura - quanto no público, em que aspectos políticos e econômicos obrigam o ajustamento.

O terceiro capítulo, "Pelas narrativas do olhar: discursos fílmicos e fotográficos", de Joana Miranda, trata da narrativa como forma de significação da experiência migratória. A partir de produções artísticas como o documentário Lisboetas e as fotografias de Sebastião Salgado, a autora tenta compreender como o ato de contar histórias ordena essas experiências. Esta primeira parte do livro tem o mérito de trazer novas informações e interessantes discussões a respeito da imigração na Europa. Apesar de diferentes contribuições e perspectivas, os textos dialogam entre si através do entendimento da complexidade cultural da situação dos imigrantes, e como seu diálogo com a sociedade receptora é fomentador de uma transformação mútua que se dá na esfera intercultural.

A segunda parte, "Representações e narrativas pós-coloniais", busca a compreensão do passado para o entendimento do presente. No primeiro texto, "Mundos locais, 
mundos globais: a diferença da história", Maria Paula Meneses chama a atenção para os limites do olhar eurocêntrico sobre a África, em que um "outro inferior" espera ser comandado pelo europeu'. Ao partir do exemplo de Moçambique, a autora discute como os modos de contar a história da colonização interferem nas representações que ainda hoje sobrevivem do negro como incapaz, o que criou uma hierarquia racial que sobrevive através dos tempos.

Em seguida, "Do pós-colonialismo do quotidiano às identidades hifenizadas: identidades em exílios pátrios?" discute os efeitos do colonialismo português nas identidades. Também utilizando Moçambique como caso exemplar, a autora Sheila Khan escutou as vozes "silenciadas" no pós-colonialismo, cruzando os depoimentos dos colonizados com as discussões de Stuart Hall na tentativa de compreender as identidades hifenizadas, híbridas que resultaram da mestiçagem.

Ao finalizar a segunda parte, "Memórias coloniais e diálogos pós-coloniais: Guiné-Bissau e Portugal" traz a questão da memória social e a necessidade de se questionar as narrativas dominantes para descentrar a compreensão da realidade. As autoras Rosa Cabecinhas e Nesilita Nhaga propõem uma análise crítica da lusofonia enquanto construção simbólica, a partir da análise das representações sociais da história. Ao analisar as memórias sobre a Guerra Colonial entre Guiné-Bissau e Portugal, o texto tenta perceber como as diferentes formas de recordar um mesmo acontecimento dão a ver os modos como cada nação interpreta o seu passado.

Uma das virtudes dessa segunda parte é trazer para a dimensão política e histórica as estratégias de representação social. A dimensão das representações do passado é interessante para a percepção do diálogo intercultural atual e apresenta pistas do futuro dessa relação entre culturas. O conceito de representação continua presente na terceira parte do livro, "Modos de representação e formas de pertença". Agora são as construções simbólicas culturais que são analisadas como parte essencial para a compreensão do diálogo entre os povos.

O primeiro texto dessa parte chama "Que és um lugar? Reflexiones antropológicas sobre lo cercano y lo remoto" e Ramon Sarró discute o espaço habitado como construção que se dá ao acúmulo de significados e ações compartilhadas que se tornam habituais². O autor discorre sobre a linguagem e sua atuação na "domesticação" do espaço, e traça uma interessante abordagem que dialoga cultura e imaginário na tentativa de perceber como a territorialização concreta dos povos parte de uma dimensão simbólica que se dá no entrecruzamento cultural. O segundo texto, "Configurações espaciais e regimes de pertença", de Luís Cunha, continua a olhar para o lugar como dimensão cultural, mas propõe uma perspectiva de narração gráfica dos locais para a percepção das representações dos diferentes discursos identitários em embate. $\mathrm{O}$ autor busca

\footnotetext{
' Stuart Hall (1997) apresenta significativas contribuições a respeito deste assunto, com uma detalhada retrospectiva histórica da transformação do olhar europeu para o africano.

${ }^{2}$ Apesar de não estarem presentes no trabalho do autor - nem serem o foco de discussão proposto - , as teorizações de Berger e Luckman (1985) sobre a formação do habitus e sua institucionalização com o tempo são esclarecedoras para a compreensão dessas tipificações recíprocas que constroem significados no local habitado.
} 
compreender a vinculação a enunciações de pertença a partir da realidade portuguesa e foca na cartografia para perceber os signos que compõem a identidade coletiva. Os dois textos presentes nesta terceira parte são significativos para percebermos como a narração do território revela como representamos e instituímos o social.

A quarta e última parte do livro, "Linguagem, discurso e trocas simbólicas" apresenta uma teorização a respeito da cultura no mundo contemporâneo. O texto "Símbolo, metáfora e mito na comunicação intercultural" propõe pensar a interculturalidade a partir da linguagem em seus aspectos centrais: símbolo, metáfora e mito. A linguagem é entendida como local de produção e reflexão do imaginário cultural próprio e também alheio, e a autora Maria Manuel Baptista utiliza o conceito de hermenêutica de Paul Ricoeur na tentativa de compreensão da comunicação com o Outro, ao apontar a cultura como possível solução para uma comunicação maior entre os povos. O fecho do livro se dá com "Syncrétisme et postmodernité", de Jean-Martin Rabot. Ao tratar de um tema aparentemente desconexo do resto da obra, a religião, o autor consegue, através da discussão sobre o sincretismo, retomar as complexas dinâmicas da sociedade contemporânea presentes na primeira parte do livro a partir da visão de uma espécie de politeísmo pós-moderno revelador da fragmentação identitária cultural. Ao utilizar o conceito de sincretismo como operador sociológico para compreender a cultura resultante de diversas migrações e a fusão de pensamentos que parece ocorrer na sociedade atual, o capítulo termina o livro de uma maneira que dialoga com todo o restante. A última parte do livro é eficiente em seu olhar para a alteridade a partir dos objetos culturais presentes na sociedade que refletem a multiplicidade de identidades presente no pós-modernismo.

Comunicação Intercultural, pode-se dizer, traz à tona um misto de elementos que, em conjunto, permitem uma visão mais complexa do mundo contemporâneo. Apesar de ter como lugar de fala a Europa, o panorama traçado por seus diversos autores fornece pistas e questões para análise em outros contextos. Para os estudos da Comunicação, Comunicação Intercultural pode ser visto como ferramenta para ajudar na compreensão dos contextos com os quais lidamos, e também pode ser aplicado em análises empíricas diversas que pretendam desvelar as dimensões comunicativas e simbólicas na linguagem dos diversos objetos culturais que compõem nossa sociedade contemporânea.

\section{REFERÊNCIAS BIBLIOGRÁFICAS}

Cabecinhas, R. \& Cunha, L. (Eds.) (2008). Comunicação intercultural. perpectivas, dilemas e desafios. Porto: Campo das Letras.

Berger, P. \& Luckman, T. (1985). A construção social da realidade. Petrópolis: Vozes.

Hall, S. (1997). Representation: cultural representations and signifying practices. London: Thousand Oaks. 


\section{NotA BIOGRÁFICA}

Renné Oliveira França é professor e pesquisador de Cinema e Audiovisual no Instituto Federal de Goiás. É pós-doutor em Comunicação Social pela Universidade Federal de Minas Gerais.

E-mail: renne.franca@ifg.edu.br

Campus Cidade de Goiás, Instituto Federal de Goiás. Quartel do XX, Praça Brasil Ramos Caiado s/n. CEP: 76600-00o. Goiás-GO, Brasil.

* Submetido: 31-01- 2016

* Aceite: 20-04-2016 